\title{
Q-Switched Erbium Doped Fiber Laser Incorporating Antimony (III) Telluride in Polyvinyl Alcohol as Saturable Absorber
}

\author{
Ezzatul Irradah Ismail ${ }^{1}$, S Muhammad Ashraf Zolkopli², Muhammad Quisar Lokman², \\ Hafizal Yahaya ${ }^{4}$, Sulaiman Wadi Harun ${ }^{5}$, Fauzan Ahmad*6 \\ 1,2,3,4,6 Malaysia Japan International Institute of Technology (MJIIT), Universiti Teknologi Malaysia, \\ 54100 Kuala Lumpur, Malaysia \\ ${ }^{5}$ Department of Electrical Engineering, University of Malaya, 50603 Kuala Lumpur, Malaysia
}

\begin{tabular}{|c|c|}
\hline Article Info & ABSTRACT \\
\hline Article history: & \multirow{9}{*}{$\begin{array}{l}\text { In this paper, we demonstrated a Q-switched erbium doped fiber laser } \\
\text { (EDFL) incorporating Antimony (III) Telluride }\left(\mathrm{Sb}_{2} \mathrm{Te}_{3}\right) \text { in polyvinyl } \\
\text { alchohol (PVA) as passive saturable absorber. The saturable absorber was } \\
\text { fabricated by dissolving Antimony (III) Telluride powder into PVA solution } \\
\text { and dry in the ambient temperature for } 48 \text { hours. Then, } 1 \mathrm{~mm}^{2} \times 1 \mathrm{~mm}^{2} \\
\mathrm{Sb}_{2} \mathrm{Te} 3 \text {-PVA film based saturable absorber were sandwiched in between } \\
\text { FC/PC ferrule for Q-switched laser generation. The stable and self-started Q- } \\
\text { switched laser operates at center wavelength } 1560 \mathrm{~nm} \text { with } 3 \mathrm{~dB} \text { bandwidth } \\
\text { of } 0.23 \mathrm{~nm} \text {. The laser operates at pump power of } 29.3 \mathrm{~mW} \text { until } 84.9 \mathrm{~mW} \\
\text { with repetition rate of } 20.99 \mathrm{kHz} \text { to } 89.29 \mathrm{kHz} \text { and pulse width of } 13.95 \mu \mathrm{s} \text { to } \\
5.10 \mu \mathrm{s} \text {. At maximum pump power, the laser able to achieve pulse energy of } \\
62.72 \mathrm{~nJ} \text { and high signal to noise ratio of } 71.4 \text {. }\end{array}$} \\
\hline Received Nov 9, 2017 & \\
\hline Revised Jan 25, 2018 & \\
\hline Accepted Feb 11, 2018 & \\
\hline & \\
\hline Keywords: & \\
\hline Antimony (III) Telluride & \\
\hline Q-Switched & \\
\hline Saturable absorber & \\
\hline
\end{tabular}

Copyright (c) 2018 Institute of Advanced Engineering and Science. All rights reserved.

\section{Corresponding Author:}

Fauzan Ahmad,

Department of Electronic Engineering System,

Malaysia Japan International Institute of Technology (MJIIT),

Universiti Teknologi Malaysia, 54100 Kuala Lumpur, Malaysia.

Email: fauzan.kl@utm.my

\section{INTRODUCTION}

The development in the generation of Q-switched fiber laser give a huge momentum in wide range of applications especially in remote sensing, range finding, laser processing and optical communications [1]. This Q-switched laser can be realized into two categories which is active or passive techniques. In active technique, an optical modulator is required to modulate the loss in the cavity. This technique enables a high stability pulse, high power and narrow pulse duration [2]. On the other hand, in the passive technique, losses are automatically modulatesd by incorporating a saturable absorber. Many types of saturable absorbers are intensively investigated, including semiconductor saturable absorber (SESAM), carbon nanotubes (CNT) and 2D materials [3]. However, SESAM's are rather costly, complex in fabrication, operates in narrow band and requires long recovery time. Besides that, CNT's are cost effective and easy to fabricate, but operates at a particular wavelength thus requiring bandgap tuning by controlling the chirality and diameter [3].

Q-switching typically is a technique to generate a short pulse by sudden switching loss of the cavity Q-factor or cavity loss. By means, switching happens when the gain achieve a maximum energy and saturates, then suddenly switches from high states to low states in the form of short and intense pulse. This phenomenon can only be realized in the presence of saturable absorber. Thus, the saturable absorber are required to have a certain optical bandgap to allow the light absorption and electron transition for pulse generation. 2D materials are excellent candidates as saturable absorber. 2D material family consists of 
several materials group, which is graphene, transition metal dichalcogenides (TMD), black phosphorus (BP) and topological insulator (TI) which offers distinct, unique optical properties thus opening up a new opportunities for fiber laser applications [2].

Antimony (III) Telluride $\left(\mathrm{Sb}_{2} \mathrm{Te}_{3}\right)$ is one of the significant $2 \mathrm{D}$ material which lies in the TI's group. Unlike two of its other family member which is Bismuth (III) Selenide and Bismuth (III) Telluride, Antimony (III) Telluride have not been receiving as many attention as it deserves, especially in Q-switched regime. Antimony (III) Telluride have a narrowed optical bandgap, approximately $0.2 \mathrm{eV}$ [4] which is $\mathrm{s}$ suitable as saturable absorber. There are several reported works on Antimony (III) Telluride as a saturable absorber using various techniques. Boguslawski et al. was able to generate a pulse laser using a liquid phase exfoliated method by dissolving the bulk Antimony (III) Telluride crystal into chitosan solution [4]. The Antimony (III) Telluride-chitosan solution were dropped on the side polished fiber for pulse generation. Though it has advantages in terms of deposition precision, this method causes the device to be highly sensitive to polarization. This can largely effect the produced pulsed if not controlled properly. In addition, Sotor et al. proposed a mechanical exfoliation technique from bulk Antimony (III) Telluride and was able to achieve more than $55 \mathrm{~dB}$ signal to noise ratio [5-6] in mode locking regime. However, this technique requires tedious works and the thickness of the exfoliated layer is rather hard to be controlled. Besides, it also causes a great number of material losses.

Thus, in this paper we proposed a method by dispersing Antimony (III) Telluride powder into a polyvinyl alcohol (PVA) as host polymer to developed Antimony (III) Telluride-polyvinyl alcohol $\left(\mathrm{Sb}_{2} \mathrm{Te}_{3}-\right.$ PVA) based passive saturable absorber. Using this method, concentration and thickness of the SA can be controlled. This method is easier to fabricate, with high repeatability and scalable production possibility. The developed Antimony (III) Telluride- polyvinyl alcohol based saturable absorber is sandwiched in between fiber-optic connector/physical contact (FC/PC) for a stable pulse generation in Q-switched regime.

\section{RESEARCH METHOD}

\subsection{Saturable Absorber Preparation}

The polyvinyl alcohol which is a water soluble synthetic polymer was dissolved in De-Ionized (DI) water with the aid of a magnetic stirrer at room temperature to obtain a polyvinyl alcohol solution. Antimony (III) Telluride-polyvinyl alcohol based saturable absorber were prepared by dissolving $10 \mathrm{mg}$ of Antimony (III) Telluride powder (Sigma-Aldrich, -325 mesh, 99.96\% trace metal basis) into $5 \mathrm{ml}$ of polyvinyl alcohol solution by ultra-sonication technique for 90 minutes, followed by centrifugation for 10 minutes at $2000 \mathrm{rpm}$ to produce a stable Antimony (III) Telluride- polyvinyl alcohol suspension. Then, the Antimony (III) Telluride- polyvinyl alcohol suspension were decanted into a $14.4 \mathrm{~cm}^{3}$ petri dish and kept in a dry cabinet at ambient temperature for 48 hours. The surface and the thickness of developed Antimony (III) Telluridepolyvinyl alcohol film based passive saturable absorber was observed and measured using 3D measuring laser microscopes (Olympus, LEXT OLS4100). The surface of the Antimony (III) Telluride- polyvinyl alcohol film consist of randomly distributed Antimony (III) Telluride powder with the measured thickness of $34 \mu \mathrm{m}$ as shown in Figure 1(a) and Figure 1(b).

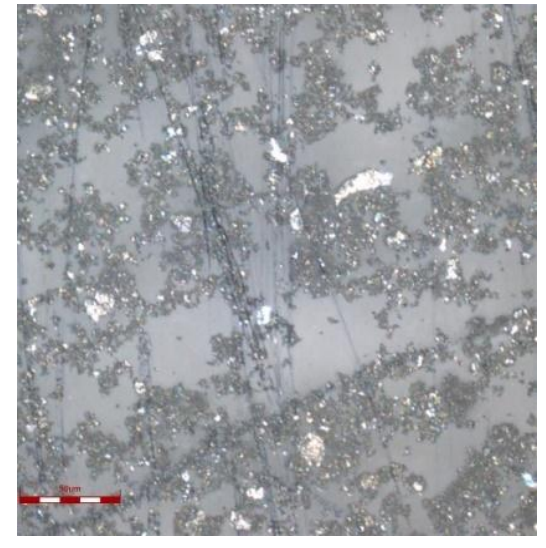

(a)

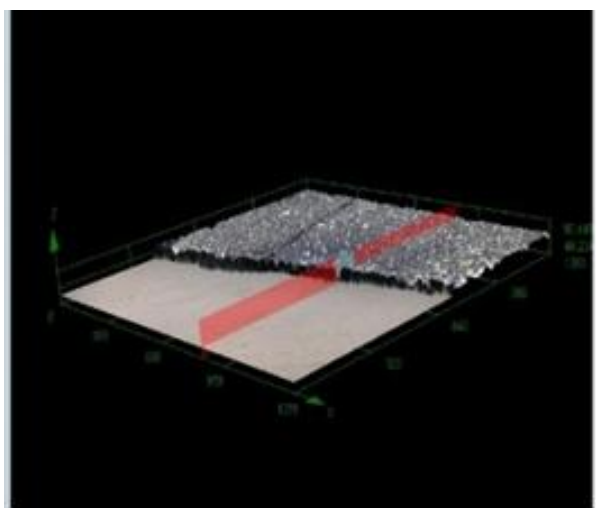

(b)

Figure 1. (a) Microscope Image of $\mathrm{Sb}_{2} \mathrm{Te}_{3}$-PVA Film (b) Thickness Measurement of $\mathrm{Sb}_{2} \mathrm{Te}_{3}$-PVA Film 


\subsection{Experimental Setup}

The experimental setup of the proposed Q-switched EDFL is shown in Figure 2. The laser cavity are comprised of $980 \mathrm{~nm}$ laser diode, 980/1550 nm wavelength division multiplexing (WDM), $2.6 \mathrm{~m}$ long Erbium doped fiber (EDF), an optical isolator, 80/20 optical coupler and the newly developed Antimony (III) Telluride- polyvinyl alcohol based passive saturable absorber. The laser was pump by a $980 \mathrm{~nm}$ laser diode through the WDM. An EDF with peak absorption of $45 \mathrm{~dB} / \mathrm{m}$ at $1531 \mathrm{~nm}$ was used to excite the $980 \mathrm{~nm}$ light to $1550 \mathrm{~nm}$ wavelength. An optical isolator was used to allow for unidirectional light propagation. The output were tapped out using $80 / 20$ coupler where $80 \%$ of light oscillates in the cavity and $20 \%$ used for output measurement. The output was measured using an optical spectrum analyzer (OSA), a digital oscilloscope, an optical power meter and a radio frequency spectrum analyzer (RFSA). The Antimony (III) Telluridepolyvinyl alcohol based saturable absorber was cut into $1 \mathrm{~mm}^{2} \times 1 \mathrm{~mm}^{2}$ and sandwiched in between FC/PC fiber ferrule for pulse laser generation.

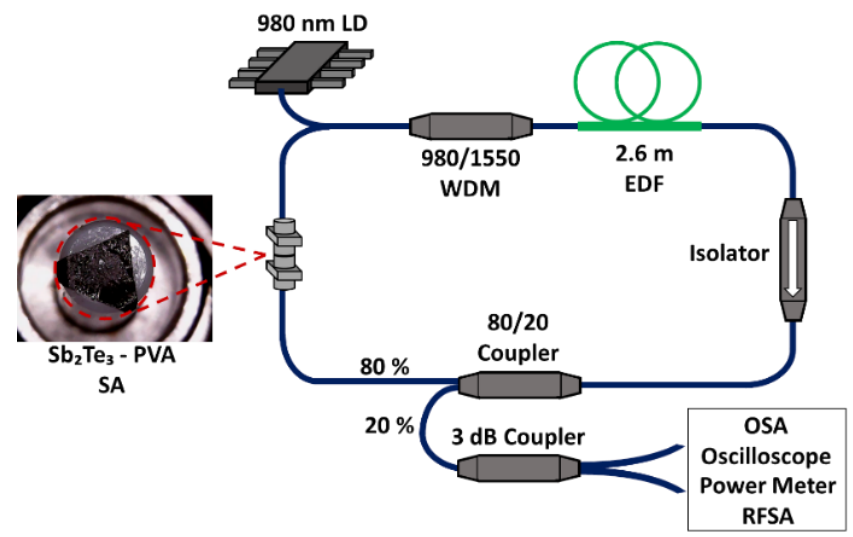

Figure 2. Laser Cavity Configuration Setup

\section{RESULTS AND ANALYSIS}

The Q-switching operation were observed at initial pump power of $29.3 \mathrm{~mW}$ and was held stable until the pump power reaches $84.9 \mathrm{~mW}$. When the pump power was tuned exceeding $84.9 \mathrm{~mW}$, the pulse started to get distorted and eventually diminished. To confirm the pulse generated were directly associated with the newly fabricated saturable absorber and not subject to the nonlinear polarization rotation (NPR) in the cavity, the saturable absorber were removed resulting in no observable pulse as the pump power was tuned over a wide range. Figure 3 shows the optical spectrum at $84.9 \mathrm{~mW}$. The laser operates at a central wavelength of $1560 \mathrm{~nm}$ with a $3 \mathrm{~dB}$ spectral bandwidth of $0.23 \mathrm{~nm}$ due to the spectral broadening induced by the Antimony (III) Telluride-polyvinyl alcohol saturable absorber

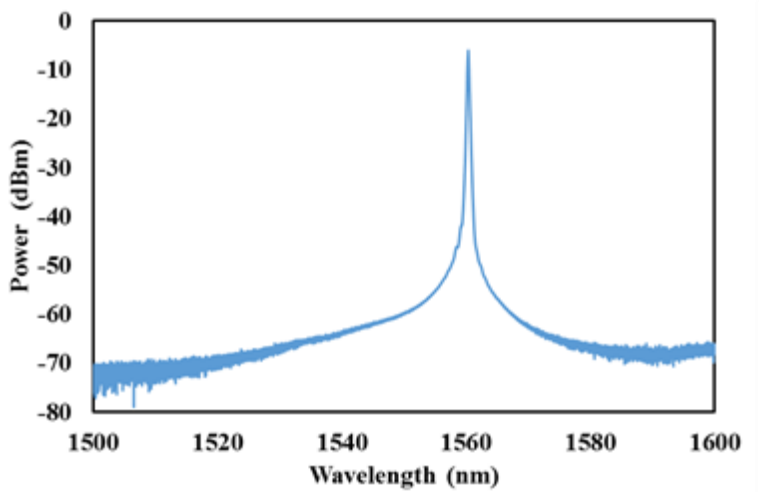

Figure 3. Optical Spectrum at Pump Power of $84.9 \mathrm{~mW}$ 
Figure 4 (a) displays the typical oscilloscope trace of Q-switched laser at maximum pump power of $84.9 \mathrm{~mW}$. The figure shows a uniform pulse with no distinct amplitude variation. The pulse duration at full width half maximum showsn in Figure 4(b) are $5.1 \mu \mathrm{s}$ and pulse-to-pulse separation of $11.2 \mu \mathrm{s}$.
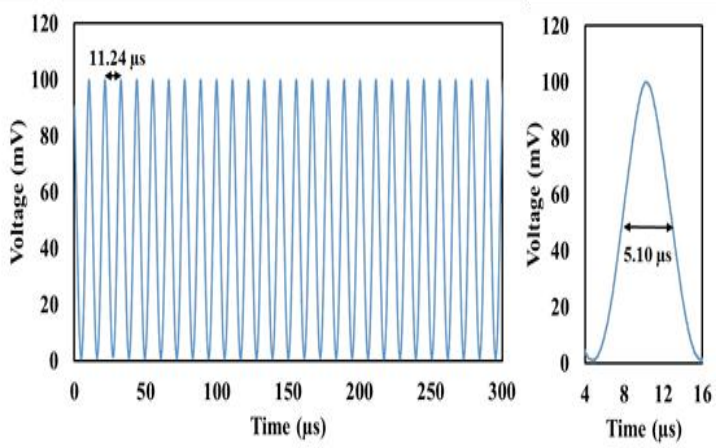

Figure 4. (a) Typical Oscilloscope Traces (b) Single Pulse at Pump Power of $84.9 \mathrm{~mW}$

Figure 5 shows the repetition rate and pulse duration as a function of pump power. The repetition rates were observed to increase from $21.0 \mathrm{kHz}$ to $89.3 \mathrm{kHz}$ as the pump power was increased from 29.3 $\mathrm{mW}$ until $84.9 \mathrm{~mW}$. On the contrary, the pulse width was decreased from $14.0 \mu$ s to $5.1 \mu \mathrm{s}$ when the pump power was increased. The increase in pump power provides more photons channeled to the saturable absorber resulting in faster saturation of the saturable absorber, thus emitting more light. Thus, the repetition rates become faster and pulse width is narrowed.

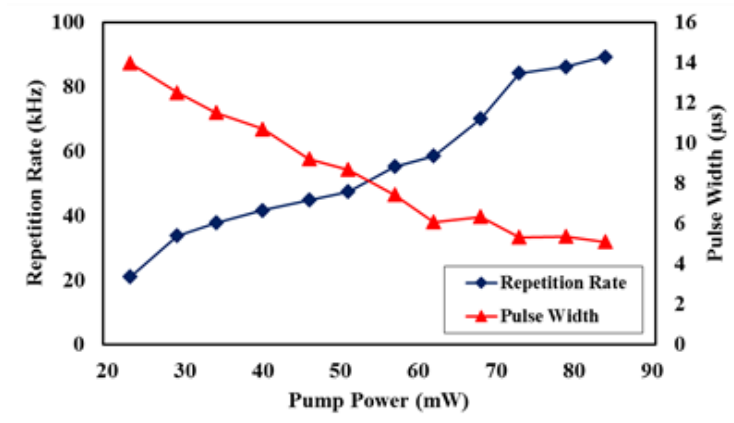

Figure 5. Repetition Rate and Pulse Width as a Function of Pump Power.

Figure 6 shows the output power and pulse energy as a function of pump power. The output power increases directly proportional to the increasing pump power, from $0.9 \mathrm{~mW}$ up to $5.6 \mathrm{~mW}$. Same goes to pulse energy, increased from $46.2 \mathrm{~nJ}$ to $67.4 \mathrm{~nJ}$ at pump power of $62.7 \mathrm{~mW}$ and decreased as the pump power was increased beyond $62.7 \mathrm{~mW}$. The increasing of repetition rate and decreasing pulse width can creates an intense pulse allowing increased pulse energy. The proposed works produce a wide range of tunable repetition rate from $20.99 \mathrm{kHz}$ to $89.30 \mathrm{kHz}$ which is better than Bismuth (III) Selenide $\left(\mathrm{Bi}_{2} \mathrm{Se}_{3}\right)$ [8,9] and Bismuth (III) Telluride $\left(\mathrm{Bi}_{2} \mathrm{Te}_{3}\right)$ [7,10] based saturable absorber. The shortest single envelope of $5.1 \mu$ s is shorter than $27.3 \mu$ s as reported in [9] using Bismuth (III) Selenide $\mathrm{Bi}_{2} \mathrm{Se}_{3}$ and $12.74 \mu$ s employing Bismuth (III) Telluride [7]. 


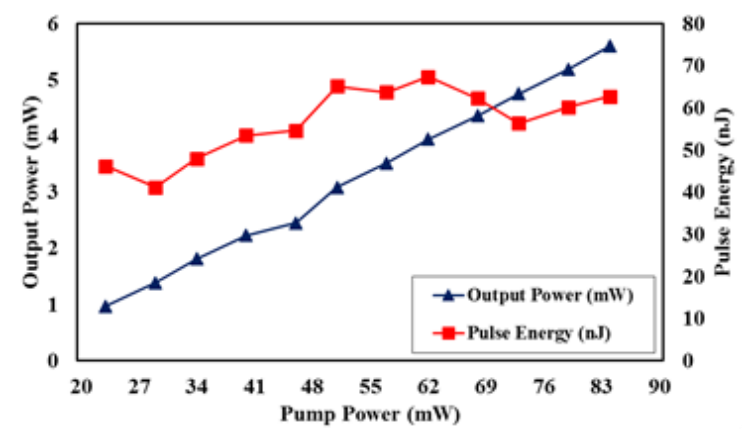

Figure 6. Output Power and Pulse Energy as a Function of Pump Power.

Figure 7 depicts the output of RFSA at fundamental repetition rate of $89.3 \mathrm{kHz}$. The recorded signal to noise ratio of the Q-switched laser is $71.4 \mathrm{~dB}$ showing that the laser have a good stability due to high signal to noise ratio. The signal to noise ratio (SNR) of $71.4 \mathrm{~dB}$ is higher than other reported works of topological insulators (Tis) based saturable absorber [8-10].

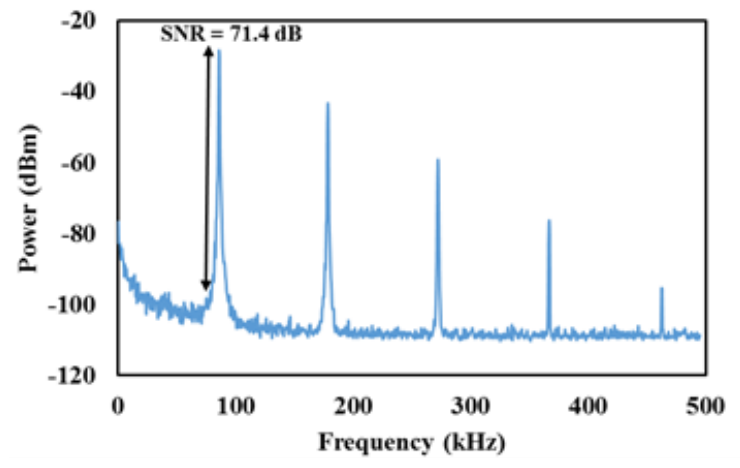

Figure 7. Signal to Noise Ratio at Fundamental Repetition Rate of $89.3 \mathrm{kHz}$

Table 1. Comparison of the Laser Performance Using Different Topological Insulator based Saturable Absorber in Q-Switched Regime

\begin{tabular}{cccccccccc}
\hline $\mathrm{SA}$ & $\square(\mathrm{nm})$ & $\begin{array}{c}\text { Pp min. } \\
(\mathrm{mW})\end{array}$ & $\begin{array}{c}\text { Pp max. } \\
(\mathrm{mW})\end{array}$ & $\mathrm{RR}(\mathrm{kHz})$ & $\mathrm{PW}(\mathrm{s})$ & $\begin{array}{c}\mathrm{AOP} \\
(\mathrm{mW})\end{array}$ & PE max. (nJ) & $\begin{array}{c}\text { SNR } \\
(\mathrm{dB})\end{array}$ & Ref. \\
\hline $\mathrm{Bi}_{2} \mathrm{Te}_{3}$ & 1567.1 & 43 & 201.7 & $3.3-12.7$ & $12.74 \square$ & 3.5 & 278.8 & - & {$[7]$} \\
$\mathrm{Bi}_{2} \mathrm{Te}_{3}$ & 1589.1 & 67 & 238.5 & $2.1-12.8$ & $13 \square$ & 19.5 & 1.525 & 36.4 & {$[10]$} \\
$\mathrm{Bi}_{2} \mathrm{Te}_{3}$ & 1543.3 & 30 & 210.0 & $12.6-177.7$ & $217 \mathrm{n}$ & 1.3 & 7.5 & - & {$[11]$} \\
$\mathrm{Bi}_{2} \mathrm{Se}_{3}$ & 974.0 & 9.3 & 150.1 & $6.2-40.1$ & $4.9 \square$ & 1.6 & 39.8 & 50 & {$[8]$} \\
$\mathrm{Bi}_{2} \mathrm{Se}_{3}$ & 1530.0 & 60 & 100.0 & $26.1-36.6$ & $27.3 \square$ & - & 6.1 & 58 & {$[9]$} \\
$\mathrm{Sb}_{2} \mathrm{Te}_{3}$ & 1560.0 & 29.3 & 84.9 & $20.9-89.2$ & $5.10 \square$ & 5.6 & 62.7 & 71.4 & This \\
\hline \multicolumn{2}{l}{$\mathrm{SA}-$ Saturable absorber, Pp - pump power, RR- repetition rate, PW- pulse width, AOP-average output power, PE- pulse energy, } \\
\hline
\end{tabular}
SNR - Signal to noise ratio, Bi2Te3- Bismuth (III) Telluride, Bi2Se3- Bismuth (III) Selenide, Sb2Te3- Antimony (III) Telluride.

\section{CONCLUSION}

As a summary, Q-switched Erbium-doped fiber laser (EDFL) incorporating Antimony (III) Telluride- polyvinyl alcohol $\left(\mathrm{Sb}_{2} \mathrm{Te}_{3}\right.$-PVA) as passive saturable absorber was demonstrated in this manuscript. The saturable absorber was prepared by dissolving Antimony (III) Telluride powder into polyvinyl alcohol solution. The Antimony (III) Telluride- polyvinyl alcohol suspension was decanted into a petri dish and left dry in the ambient for 48 hours. The saturable absorber was deposited in between the fiber- 
connector/physical contact (FC/PC) with fiber connector to generate pulse laser. The stable Q-switched laser operates on threshold input pump power of $29.3 \mathrm{~mW}$ and was sustained until $84.9 \mathrm{~mW}$. The laser operates at center wavelength of $1560 \mathrm{~nm}$. As the pump power increased, the repetition rate was increased and pulse width decreased. The highest pulse energy were achieved at $67.4 \mathrm{~nJ}$ at input pump power of $62.7 \mathrm{~mW}$. The output power was directly proportional to the input pump power. The recorded signal to noise ratio (SNR) of $71.4 \mathrm{~dB}$ shows the high stability of the generated pulse which is also the highest recorded signal to noise ratio reported among topological insulator based passive saturable absorber.

\section{ACKNOWLEDGEMENTS}

The authors thank Universiti Teknologi Malaysia (UTM) for supporting this research work UTM R\&D Fund grant no: 4J304 and Malaysia Japan International Institute of Technology (MJIIT) Scholarship Fund

\section{REFERENCES}

[1] S. Chen, Y. Chen, M. Wu, Y. Li, C. Zhao, S. Wen, "Stable Q-Switched Erbium-Doped Fiber Laser Based on Topological Insulator Covered Microfiber," IEEE Photonics Technology Letters, vol. 26, no. 10, pp. 987-990, May 2015.

[2] R.I. Woodward and E. J. R. Kelleher, "2D Saturable Absorbers for Fibre Lasers,” Appl. Sci., vol. 5, no. 4, pp. 14401456, 2015.

[3] S. Yamashita, A Tutorial on Nonlinear Photonic Applications of Carbon Nanotube and Graphene", Journal of Lightwave Technology, vol. 30, no. 4, pp. 427-477, February 15, 2012.

[4] J. Boguslawski, J. Sotor, G. Sobon, J. Tarka, J. Jagiello, W. Macherzynski,L. Lipinska and K. M. Abramski, "Mode-locked Er-doped fiber laser based on liquid phase exfoliated Sb2Te3 topological insulator," Laser Phys., 24,105111 (6pp), 2014.

[5] J. Sotor, G. Sobon, W. Macherzynski and K. M. Abramski, "Harmonically mode-locked Er-doped fiber laser based on a Sb2Te3 topological insulator saturable absorber," Laser Phys. Lett., 11, 055102 (5pp), 2014.

[6] J. Sotor, G. Sobon,W. Macherzynski, P. Paletko,K. Grodecki, and K. M. Abramski, "Mode-locking in Er-doped fiber laser based on mechanically exfoliated Sb2Te3 saturable absorber," Optical Materials Express, vol. 4, no. 1, pp.1- 6, 1 January 2014.

[7] Q. Wang, Y. Chen, G. Jiang, et al., "Drop-casted self-assembled topological insulator membrane as an effective saturable absorber for ultrafast laser photonics," IEEE Photonics Journal, vol. 7, no. 2, pp. 1-11, 2015.

[8] L. Sun, Z. Lin, J. Peng, et al., "Preparation of few-layer bismuth selenide by liquid-phase-exfoliation and its optical absorption properties," Scientific Reports, Article number: 4794 ,2014.

[9] H. Ahmad, M. Soltanian, L. Narimani, et al., "Tunable S-Band Q-Switched Fiber Laser using Bi2Se3 as the saturable absorber," IEEE Photonics Journal, vol. 7, no. 3, 2015.

[10] Y. Chen, C. Zhao, S. Chen, et al., "Large energy, wavelength widely tunable, topological insulator Q-switched erbium doped fiber laser," IEEE Journal of Selected Topics in Quantum Electronics, vol. 20, no. 5, pp. 315-322, 2014.

[11] M. Wu, Y. Chen, H. Zhang, et al., "Nanosecond-switched erbium-doped fiber laser with wide pulse-repetition- rate range based on topological insulator," IEEE Journal of Quantum Electronics, vol. 50, no. 6, pp. 393-396, 2014. 


\section{BIOGRAPHIES OF AUTHORS}

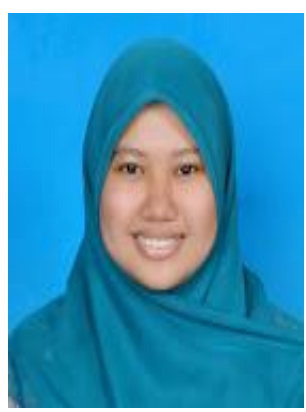

Ezzatul Irradah Ismail received her B.Sc.(Hons) degree in Applied Physics from Universiti Malaysia Terengganu, Malaysia in 2015, and M.Eng degree in engineering science from University of Malaya, Malaysia in 2017. She is currently pursuing her PhD in Physics (Photonics Engineering) at Malaysia-Japan International Institute of Technology (MJIIT), Universiti Teknologi Malaysia.

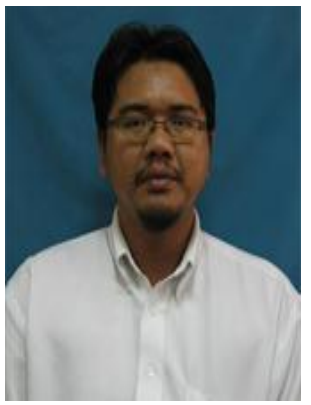

Fauzan Ahmad received the Degree in Mechatronics from Universiti Teknologi Malaysia in 1999, Master's Degree (Image processing) and $\mathrm{PhD}$ Degree in Electrical Engineering (Photonicss) from University of Malaya in 2007 and 2014, respectively. He is currently a senior lecturer at Department of Electronic Systems Engineering, Malaysia-Japan International Institute of Technology (MJIIT), Universiti Teknologi Malaysia. Dr. Fauzan is a member of Optical System and Devices (ODESYS) Ikohza of MJIIT and his research interest includes nano material for optical pulse laser generation and optical fiber sensor.

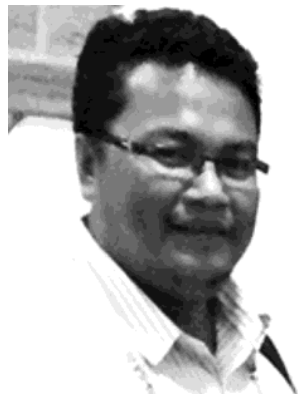

Sulaiman Wadi Harun received the B.Eng. degree in electrical and electronics system engineering from the Nagaoka University of Technology, Nagaoka, Japan, in 1996, and the M.Sc. and Ph.D. degrees in photonics from the University of Malaya, Kuala Lumpur, Malaysia, in 2001 and 2004, respectively. He is currently a Full Professor at the Faculty of Engineering, University of Malaya. His research interests include fiber optic active and passive devices. 